\title{
Water resources planning and management based on system dynamics: a case study of Yulin city
}

\author{
Xiao-jun Wang • Jian-yun Zhang • Jiu-fu Liu • Guo-qing Wang • \\ Rui-min He $\cdot$ Amgad Elmahdi $\cdot$ Sondoss Elsawah
}

Received: 23 May 2009/Accepted: 24 August 2010/Published online: 15 September 2010

(C) Springer Science+Business Media B.V. 2010

\begin{abstract}
Water security is an integral aspect of the socio-economic development in China. Nevertheless, water resources are under persistent pressures because of the growing population, heavy irrigation, climate change effects and short-term policies. Traditional management approaches narrowly focus on increasing supply and reducing demand without considering the complex interactions and feedback loops that govern water resource behaviour. Whereas these approaches may provide quick fix solutions, they often lead to unanticipated, sometimes catastrophic, delayed outcomes. Therefore, water management needs to take a holistic approach that caters to the interdependent physical
\end{abstract}

Readers should send their comments on this paper to BhaskarNath@aol.com within 3 months of publication of this issue.

X. Wang $(\varangle) \cdot$ J. Liu

Department of Hydrology and Water Resources, Nanjing Hydraulic Research Institute,

210029 Nanjing, China

e-mail: nhri501@yahoo.com.cn

J. Liu

e-mail: jfliu@nhri.cn

J. Zhang $\cdot$ G. Wang $\cdot$ R. He

Research Centre for Climate Change, Ministry of Water Resources, 210029 Nanjing, China e-mail: jyzhang@nhri.cn

G. Wang

e-mail: gqwang@nhri.cn

R. He

e-mail: rmhe@nhri.cn

A. Elmahdi

Urban Water Balance, Climate and Water Division, Bureau of Meteorology, Melbourne 3008, Australia

e-mail: A.Elmahdi@bom.gov.au

S. Elsawah

Integrated Catchment Assessment and Management (iCAM), Australian National University, Canberra, Australia 
(e.g. water inflows, outflows) and behavioural (e.g. decision rules, perceptions) processes in the system. Unlike reductionist approaches, System Dynamics (SD) takes a system-level view for modelling and analysing the complex structure (cause-effect relationships, feedback loops, delays) that generates the systemic behaviour. Simulating the SD model allows assessing long-term system-wide impacts, exploring leverage points and communicating results to decision makers. In this paper, we follow an SD modelling approach to examine the future of water security in Yulin City. First, we present a conceptual model for integrating water supply and demand. Based on this, we build an SD model to simulate and analyse the dynamics of water resource over time. The model output is tested to ensure that it satisfactorily replicates the historical behaviour of the system. The model is used to quantitatively assess the effectiveness of various supply/demand management options. Three scenarios are designed and examined: business-as-usual, supply management, and demand management. Results show that current management regime cannot effectively meet the future water demand. Whereas supply acquisition provides short-term benefits, it cannot cope with the growing population. A combination of conservation measures and demand-management instruments is regarded the most effective strategy for balancing supply and demand.

Keywords System dynamics · Water resources - Water demand management . Water conservation · Yulin city

\section{Introduction}

Water is inextricably linked with every aspect of life, including food security, human health, economic development and ecological balance. Water shortage is regarded as one of the most challenging environmental problem in the twenty-first century (Brown and Flavin 1999). This threatens food security, economic development and ecological balance.

During the twentieth century, the ultimate objective of water management was to satisfy the growing requirements of the fast development pace. For this, command-and-control approaches were used to increase the capacity to access water supplies (Holling and Meffe 1996). This included massive infrastructure projects, such as building additional dams and drilling deeper for water.

Whereas infrastructure projects provided solutions for chronic water crises, they could not cope with the persistent pressures of population growth, climate change effects, waterintensive agriculture and more. In addition, they have come at expensive, irreversible socio-ecological costs (Brierley and Fryirs 2008). For example, the shrinking of the Aral Sea, formerly the world's fourth largest lake, illustrates the catastrophic outcomes of shortterm water planning policies (Glantz 1999). As a result, there has been almost consensus that command-and-control approaches are no longer adequate to deal with the complexity and uncertainty inherent in contemporary water management (Born and Sonzogni 1995); (Hjorth and Bagheri 2006).

Recently, there has been a shift towards integrated management that takes a holistic view of the interdependent hydrological, ecological and socio-economic processes that influence water resource (Jakeman et al. 2005). The objective is to design policies that compromise goals relevant to the triple pillars of sustainability: ecology, society and economy. The concepts of integrated management have been widely used. Examples include (Stephenson 1999; Butler and Memon 2006; Gumbo 2004; Wheida and Verhoeven 2007). 
Integrated water-management policies need to be guided by an informed understanding of the system, its processes and responses to various changes. Nevertheless, water management arises in the context of complex and interdependent ecological, social and economic systems whose behaviour is governed by numerous feedback interactions and delays that are characterized by non-linear and counter-intuitive behaviour. Failure to consider such dynamic complexity often leads to unanticipated, policy resistant and, sometimes, catastrophic situations.

System Dynamics (SD) provides a feedback-oriented modelling framework for learning and communicating about the inherent complexity of water management. SD is designed for modelling and analysing complex socio-economic systems. It has been widely applied in many environmental problems, including water management (Winz et al. 2009).

This paper presents a dynamic simulation model of a water system in Yulin City and analyses the effectiveness of various supply and demand policies in meeting socio-economic and ecological requirements. Three scenarios are examined and reported: businessas-usual, capacity acquisition, and price-control. Results suggest that demand management represents the leverage point for achieving long-term sustainability outcomes.

The paper is organized as follows: Section 2 introduces SD modelling. The case study is introduced in Sect. 3. The followed methodology is described in Sect. 4. Simulation results are reported and discussed in Sect. 5. Finally, we wrap up with the conclusion.

\section{System dynamics modelling}

System Dynamics (SD) is a rigorous methodology for thinking, visualising and communicating about the future evolution of complex systems by creating qualitative and quantitative causal models which captures the interrelationships of the physical (e.g. water inflows, outflows) and behavioural (e.g. decision rules, perceptions) processes in the system (Wolstenholme 1990). Based on Systems Thinking, SD takes a system-level view for analysing complex problems by modelling the causal structure deriving the problematic behaviour (e.g. cause-effect interrelationships, feedback loops, delays, non-linearity) (Sterman 2000). Simulating the SD model shows the delayed and systemic impacts of alternative policies in a time-compressed manner (Sterman 1994).

Usually, an SDM project consists of the following phases: problem definition, system conceptualization, model formulation, model evaluation/testing, policy analysis and implementation (Karavezyris et al. 2002; Xu et al. 2002; Ahmad and Simonovic 2004; Elmahdi et al. 2007; Zhang et al. 2008). It is important to determine the positive and negative relationships between variables, feedback loops, system archetypes and delays. Then with the initial conditions for the first time step, the SD model can take certain steps along the time axis in the simulation process. All system dynamics model consists of the following basic elements, which are shown in Fig. 1.

Software tools like Stella, Dynamo, Vensim and Powersim use the principles of object-oriented programming for the development of system dynamics simulation programs. They provide a set of graphical objects with their mathematical functions for easy representation of the system structure and the development of computer code. Simulation models can be easily and quickly developed using these software tools (Guo et al. 2001; Sun et al. 2002; Xu et al. 2002; Ahmad and Simonovic 2004; Elmahdi et al. 2007; Zhang et al. 2008). The following equations show the basic mathematical form of the Vensim modelling language. 


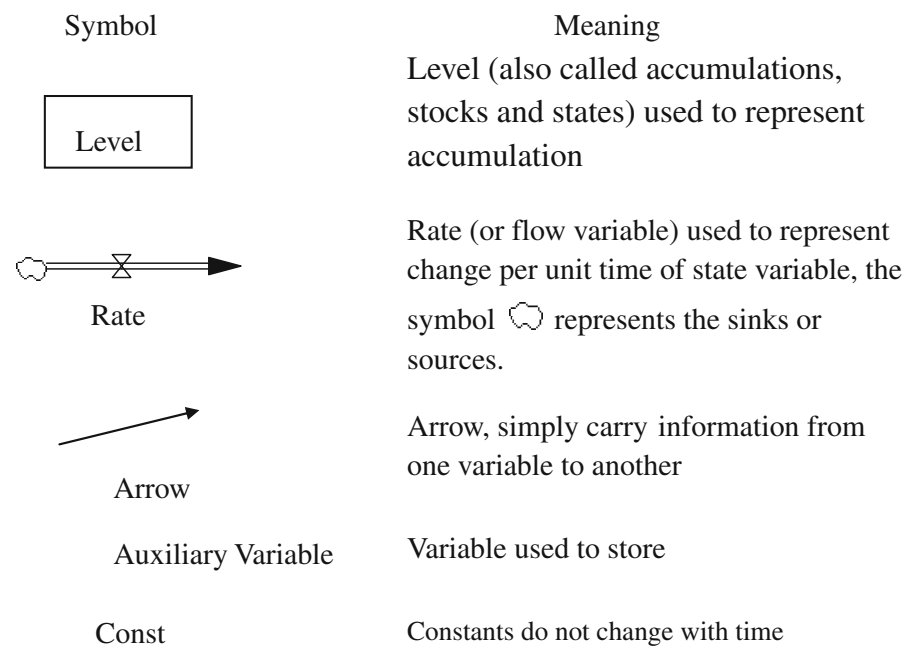

Fig. 1 Basic element for system dynamics model

$$
\begin{aligned}
\text { Levels }_{t}=\int_{0}^{T} \text { Rates }_{t} \mathrm{~d} t \text { or } \frac{\mathrm{d}}{\mathrm{d} x} \text { Levels }_{t}=\text { Rates }_{t} \\
\text { Rates }_{t}=f\left(\text { Levels }_{t}, \text { Aux }_{t}, \text { Data }_{t}, \text { Const }\right) \\
\text { Aux }_{t}=g\left(\text { Levels }_{t}, \text { Aux }_{t}, \text { Data }_{t}, \text { Const }\right) \\
\text { Data }_{t}=h\left(\text { Levels }_{t}, \text { Aux }_{t}, \text { Data }_{t}, \text { Const }\right)
\end{aligned}
$$

In these equations $f, g$ and $h$ are arbitrary, non-linear, potentially time varying and vector-valued functions. Equation 1 represents the evolution of the system over time, Eq. 2 the computation of the rates determining that evolution, Eq. 3 the intermediate results necessary to compute the rates and Eq. 4 the initialization of the system. Equation 1 above is written using both integral and differential notation. The format that vensim uses for expressing equations matches more closely the first, but the two equations have the same meaning (http://www.vensim.com).

\section{Case study area}

Yulin locates at latitude $36^{\circ} 57^{\prime}-39^{\circ} 35^{\prime} \mathrm{N}$ and longitude $107^{\circ} 28^{\prime}-111^{\circ} 15^{\prime} \mathrm{E}$; encompassed within the administrative boundaries are 12 counties at a combined territory of $43,578 \mathrm{~km}^{2}$, which are shown in Fig. 2. The annual rainfall is about $400 \mathrm{~mm}, 75 \%$ of which is concentrated in June, July and August, the mean annual runoff is $22.9 \times 10^{8} \mathrm{~m}^{3}$, equivalent to the mean runoff depth of $52 \mathrm{~mm}$, the groundwater resources of the whole city is $24.78 \times 10^{8} \mathrm{~m}^{3}$, as the duplicative amount is $15.6 \times 10^{8} \mathrm{~m}^{3}$, the gross mean annual potential of water resources is estimated at $32.01 \times 10^{8} \mathrm{~m}^{3}$. The water resource per capita in Yulin is $910 \mathrm{~m}^{3} / \mathrm{p}$ in 2005 , and the scarcity of water resources had handicapped the development of city in the past years. 


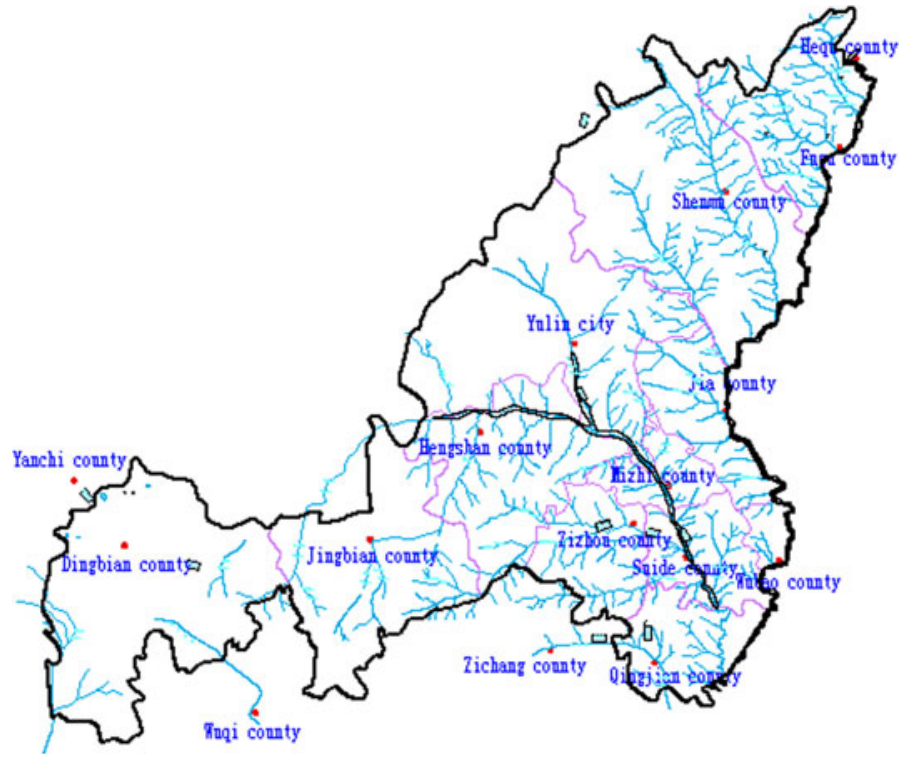

Fig. 2 Sketch map of the study area

\section{Methodology}

In this paper, we follow an SD modelling approach to analyse the dynamics of supply and demand and develop a model that can be used to simulate the changes in water balance over time.

\subsection{Problem articulation}

To articulate the problem, we start by defining the main issues that are relevant to water resource management in Yulin. Figure 3 presents a conceptual framework of these issues, categorized into supply, demand and price adjustment.

\subsection{System interaction}

\subsubsection{Water demand}

According to the water resources planning technical specifications in China, total water demand includes production water demand, domestic water demand and ecological water demand (Zhang 2005). They can be estimated by the following equations.

$$
W_{p}^{t}=L W_{i}^{t}+P W_{j}^{t}+E W_{k}^{t}
$$

In which,

$$
L W_{i}^{t}=L u W_{i}^{t}+L r W_{i}^{t}=P u_{i}^{t} \cdot L Q u_{i}^{t} \cdot 365 / 1000+\underset{i}{\operatorname{Pr}} \cdot L Q r_{i}^{t} \cdot 365 / 1000
$$




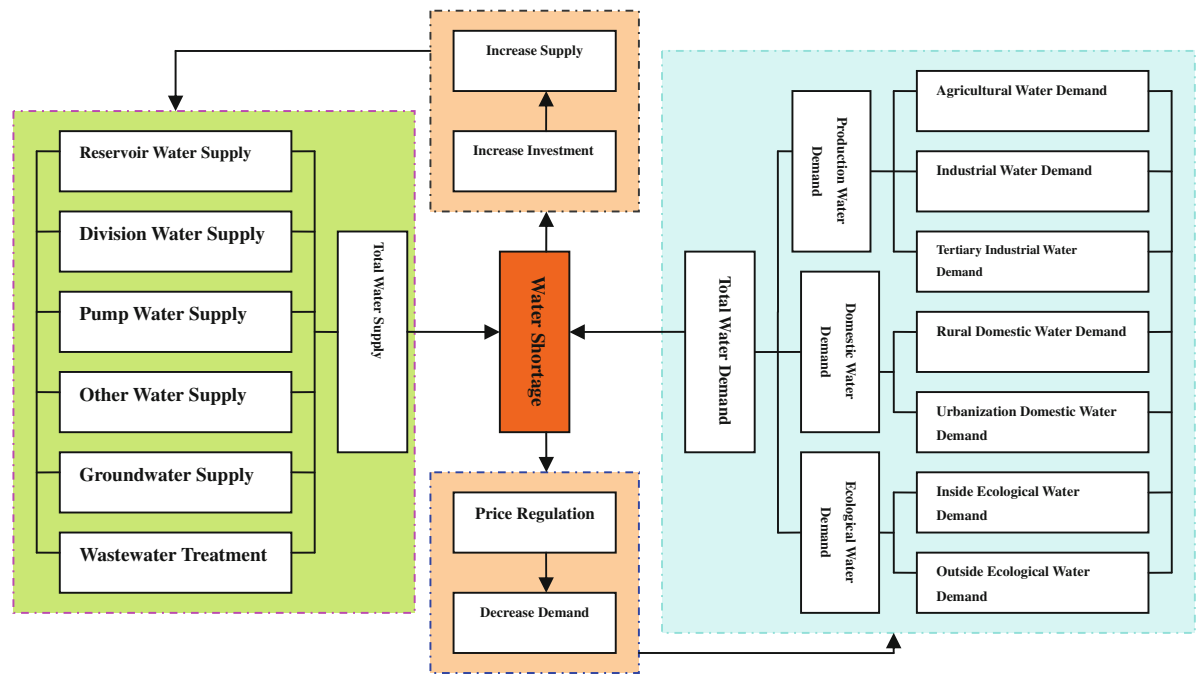

Fig. 3 Overall conceptual diagrams for Water resources planning and management

$$
\begin{gathered}
P W_{j}^{t}=A W_{i}^{t}+I W_{j}^{t}+T W_{k}^{t}=\sum_{j=1}^{3}\left(S_{j}^{t} \cdot A Q_{n}\right)+S n_{i} \cdot m_{i}+M r \cdot A+\sum_{i=1}^{n}\left(X_{i}^{t} \cdot I Q_{i}^{t}\right) \\
E W_{k}^{t}=E_{\text {in }} W_{k}^{t}+E_{\text {out }} W_{k}^{t}
\end{gathered}
$$

Where $i, j, k$ is different department for water demand, $t$ is time, $W_{p}^{t}$ is the total water demand $\left(10^{4} \mathrm{~m}^{3}\right)$.

$L W_{p i}^{t}$ is the domestic water demand $\left(10^{4} \mathrm{~m}^{3}\right)$, which includes those quantities of water consumed in a given period for all residential purposes such as in-house water use for kitchen, laundry and bath, as well as outside uses in gardens. It can be estimated by multiplying the projected population $\left(10^{4} \mathrm{p}\right)$ with the projected per capita water consumption (1/p.d), and the methods are distinct for urban and rural area. As for urban population, urban water demand $L u W_{i}^{t}$ is estimated by multiplying the urban population $P u_{i}^{t}\left(10^{4} \mathrm{p}\right)$ with the per capita water consumption for urban $L Q u_{i}^{t}(1 / \mathrm{p} . \mathrm{d})$, and for rural water demand $L r W_{i}^{t}$, it is estimated by multiplying the rural population $\operatorname{Pr}_{i}^{t}\left(10^{4} \mathrm{p}\right)$ with the per capita water consumption for rural $L Q r_{i}^{t}$ (1/p.d) (Zhang 2005).

$P W_{j}^{t}$ is the production water demand $\left(10^{4} \mathrm{~m}^{3}\right)$, which includes different departments for water demand of the national economy. Usually, we classify them into agricultural water demand $A W_{i}^{t}$, industrial water demand $I W_{j}^{t}$ and tertiary industrial water demand $T W_{k}^{t}$. Agricultural water demand generally accounts for more than $70 \%$ of the total demand and normally includes irrigation water demand, fisheries water demand and animal husbandry water demand. In this paper, irrigation water demand is estimated by the total irrigation area multiplied by the quotas. Fisheries water demand can also be estimated by multiplying fishery area $\left(10^{4} \mathrm{p}\right)$ with the quotas of fishery. Methods for animal husbandry water demand is the same with domestic water demand, it is estimated by multiplying the number of livestock $\operatorname{Pr}_{i}^{t}\left(10^{4} \mathrm{p}\right)$ with the quotas of animal husbandry $L Q r_{i}^{t}(1 / \mathrm{p} . \mathrm{d})$. And for industrial water demand $I W_{j}^{t}$ and tertiary industrial water demand $T W_{k}^{t}$, they can be estimated as the product of the industrial production with the corresponding water-demand per unit of industrial production (Zhang 2005). 
$E W_{k}^{t}$ is the ecological water demand $\left(10^{4} \mathrm{~m}^{3}\right)$, which includes water demand for environment protection and ecological system. In this paper, water demand for environment protection is studied, and it is assumed by multiplying urbanization population $\operatorname{Pr}_{i}^{t}$ $\left(10^{4} \mathrm{p}\right)$ with the quota for urbanization ecology $L Q r_{i}^{t}$ (1/p.d) (Zhang 2005).

\subsubsection{Water supply}

Typically, the main potential sources of water supply include surface water (dams and water harvesting techniques), groundwater (wells and boreholes) and other sources including reuse of water and purification of effluent (Zhang 2005). In this paper, we estimated water supply by the following formula:

$$
S W^{t}=S W_{s}^{t}+S W_{g}^{t}+S W_{o}^{t}
$$

where $S W^{t}$ is total water supply, $S W_{s}^{t}$ is surface water supply, which includes reservoir, diversion water supply and pump water supply, $S W_{g}^{t}$ is groundwater supply, $S W_{o}^{t}$ is other kinds of water supply, mainly include wastewater reuse and collection of rainwater. But something should mention, water supply obey to physical capacity and environmental constraints.

\subsubsection{Demand-management instrument}

Water price is widely considered by economists as a key instrument in assisting the implementation of an efficient allocation of limited water resources by providing appropriate signals and incentives. As we know, price and supply act as a balancing loop; as price increases, desired supply raises and causes the supply to increase (Stephenson 1999; Savenije and van der Zaag 2002; Rogers et al. 2002; Butler and Memon 2006). An increase in supply decreases price.

Economics calculate the elasticity as:

$$
\varepsilon=\frac{d Q / Q}{d p / p}
$$

where $\varepsilon$ is elasticity, $Q$ is quantity and $p$ is price. Elasticity is a negative number, since demand expected to decrease as price increases. If assume $\varepsilon$ is constant, then

$$
\begin{aligned}
\int \frac{d Q}{Q} & =\varepsilon \int \frac{d p}{p} \\
Q & =k p^{\varepsilon}
\end{aligned}
$$

where $k$ is a constant.

Then can get

$$
Q_{2}=Q_{1}\left(\frac{p_{2}}{p_{1}}\right)^{\varepsilon}
$$

where $p_{1}$ and $p_{2}$ are water price before and after adjustment, $Q_{1}$ and $Q_{2}$ are quantities before and after adjustment. So, adjustment of the water price of is one of most effective economic levers for water supply and demand. But one thing should mentioned, that is how to set a reasonable price, many of the research papers also studied this problem in the past years. As in this paper, we calculate water price as: 


$$
P=P_{1}+P_{2}+P_{3}
$$

where $P_{1}, P_{2}$ and $P_{3}$ is resource Price, engineering Price and environment Price, respectively.

\subsection{Model conceptualization}

Based on the described conceptual framework, we use Causal Loop Diagram (CLD) to capture the interactions between economic development, population growth, water investment, irrigation water demand, industrial water demand, tertiary industrial water demand, surface water supply, groundwater supply, water price as well as water pollution in Yulin city. The feedback structure is further developed, as to represent the influence factors for co-operation in more detail, which is shown in Fig. 4. In which, each arrow indicates an influence of one element on another. This influence is considered as positive (+) if an initial change is amplified in the same direction as all components are traced through the loop, or negative (-) if an increase in one element causes a decrease in another (Karavezyris et al. 2002; Xu et al. 2002; Yu et al. 2003; Ahmad and Simonovic 2004; Zhang 2005; Elmahdi et al. 2007; Zhang et al. 2008). The hypotheses about these influences are based on literature studies as well as works previously carried out at our research unit.

From Fig. 3, the fundamental feedback structure for the YulinSD that embodies six feedback loops could be obtained. These are referred to as:

R1: Economic Development $\rightarrow+$ Domestic Water Demand $\rightarrow+$ Total Water Demand $\rightarrow$ + Water Shortage Rate $\rightarrow-$ Economic Development

R2: Economic Development $\rightarrow$ +Production Water Demand $\rightarrow$ +Total Water Demand $\rightarrow$ + Water Shortage Rate $\rightarrow-$ Economic Development

R3: Economic Development $\rightarrow+$ Ecology Water Demand $\rightarrow+$ Total Water Demand $\rightarrow$ + Water Shortage Rate $\rightarrow-$ Economic Development

R4: Economic Development $\rightarrow+$ Domestic Water Demand $\rightarrow+$ Total Water Demand $\rightarrow$ + Water Shortage Rate $\rightarrow$-Water Supply $\rightarrow+$ Water Price $\rightarrow-$ Total Water Demand $\rightarrow$

- Water Shortage Rate $\rightarrow+$ Economic Development

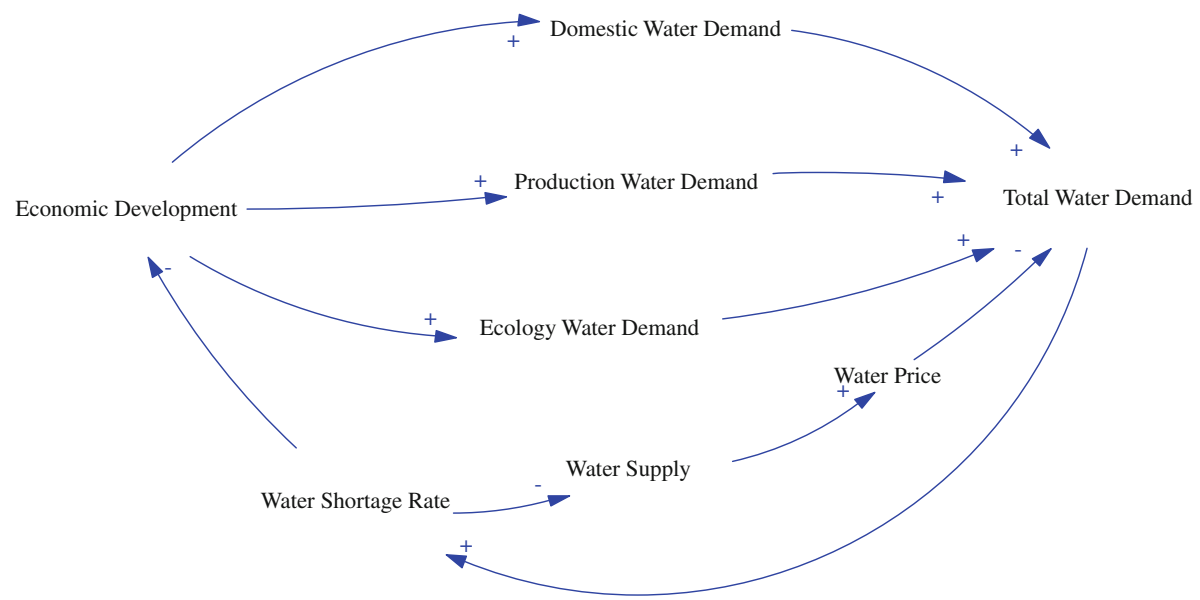

Fig. 4 Causal loop diagram of the basic model for YulinSD 
R5: Economic Development $\rightarrow$ +Production Water Demand $\rightarrow$ +Total Water Demand $\rightarrow$ + Water Shortage Rate $\rightarrow-$ Water Supply $\rightarrow+$ Water Price $\rightarrow-$ Total Water Demand $\rightarrow$

- Water Shortage Rate $\rightarrow+$ Economic Development

R6: Economic Development $\rightarrow+$ Ecology Water Demand $\rightarrow+$ Total Water Demand $\rightarrow$ + Water Shortage Rate $\rightarrow$-Water Supply $\rightarrow+$ Water Price $\rightarrow-$ Total Water Demand $\rightarrow$ - Water Shortage Rate $\rightarrow+$ Economic Development

\subsection{Model formulation}

As the key elements defined, these have to be quantified as variables and their influences have to be formulated mathematically. The WMM is definitively determined when the parameters and the start values for the state variables (stocks) have been specified. The YulinSD model in this study has been developed within Vensim Personal Learning Edition (PLE), and the boundary of the model is the total administrative area of Yulin city. The strategic planning period ranges from 1980 to 2030. The model includes 139 parameters and three major subsystems; the flow diagram for Yulin city is shown in Fig. 5. Vensim PLE makes it possible to develop a complex water resources model with less programming

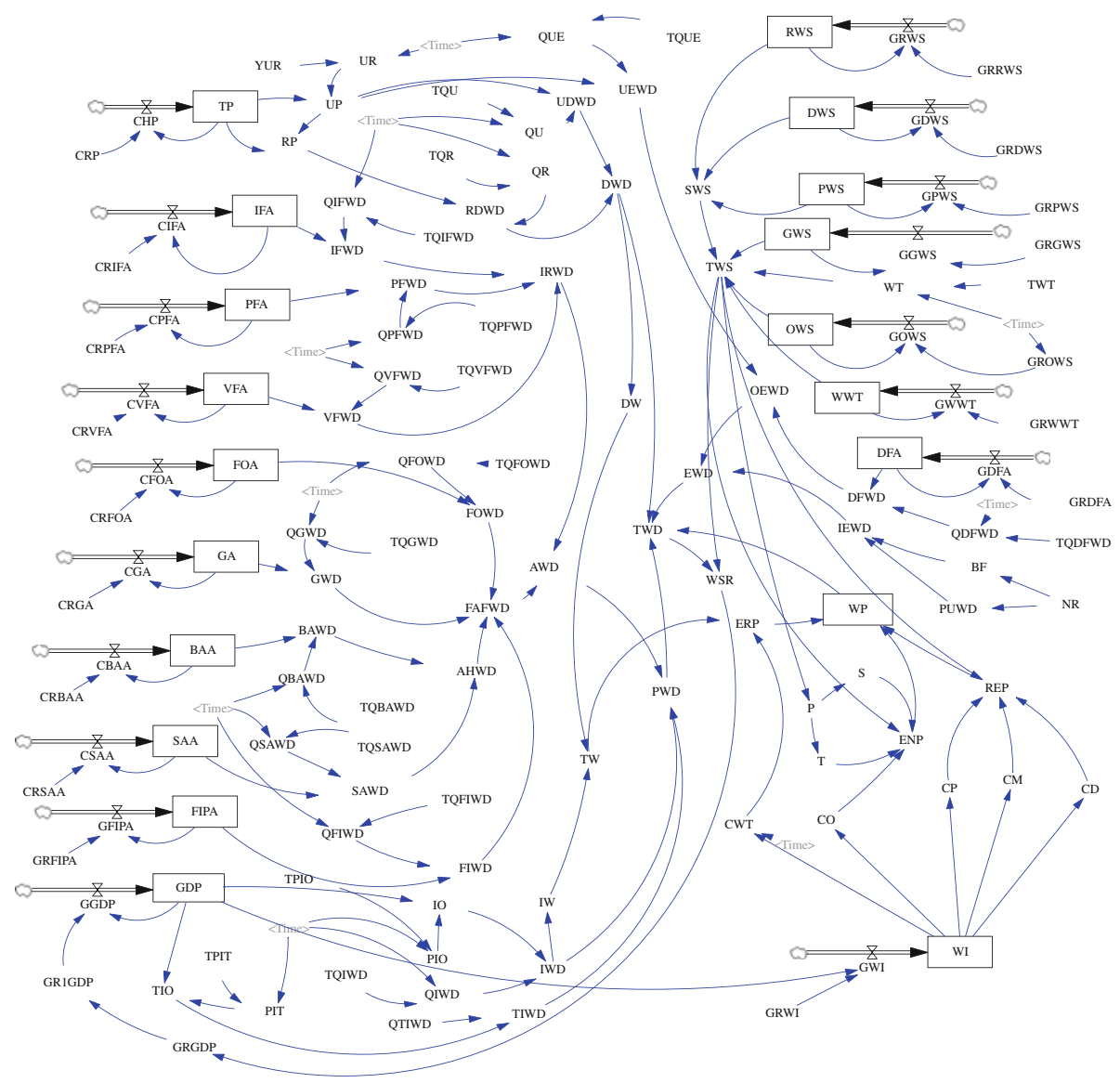

Fig. 5 Flow diagrams for water resources planning and management in Yulin city 
Fig. 6 Population growth of the base run

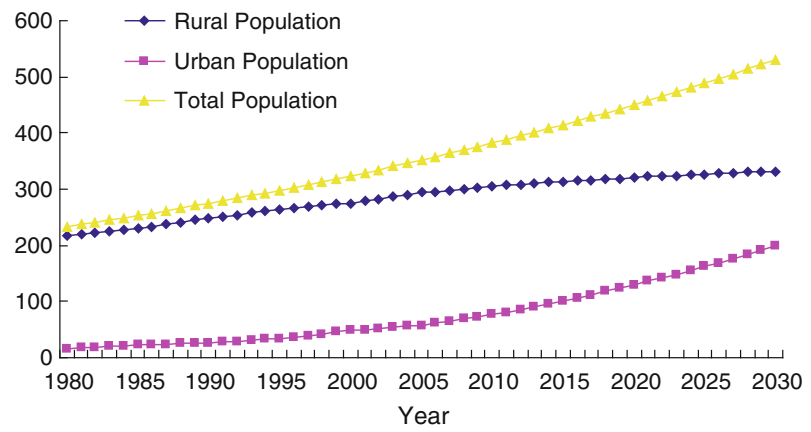

Table 1 Compared result of simulated values and actual value of the main variables

\begin{tabular}{|c|c|c|c|c|c|c|}
\hline \multirow[t]{2}{*}{ Variables } & \multicolumn{3}{|l|}{2000} & \multicolumn{3}{|l|}{2005} \\
\hline & $\begin{array}{l}\text { Actual } \\
\text { value }\end{array}$ & $\begin{array}{l}\text { Simulated } \\
\text { value }\end{array}$ & $\begin{array}{l}\text { Relative } \\
\text { error }\end{array}$ & $\begin{array}{l}\text { Actual } \\
\text { value }\end{array}$ & $\begin{array}{l}\text { Simulated } \\
\text { value }\end{array}$ & $\begin{array}{l}\text { Relative } \\
\text { error }\end{array}$ \\
\hline Total population $\left(10^{4}\right.$ people $)$ & 317.80 & 323.99 & 1.95 & 351.63 & 351.79 & 0.05 \\
\hline Urbanization Population $\left(10^{4}\right.$ people $)$ & 47.28 & 48.59 & 2.77 & 58.89 & 58.04 & -1.44 \\
\hline Vegetable field area $\left(10^{3} \mathrm{ha}\right)$ & 12.5 & 13.05 & 4.40 & 18.58 & 21.02 & 13.13 \\
\hline Agricultural water Demand $\left(10^{4} \mathrm{~m}^{3}\right)$ & 52854 & 49895 & -5.60 & 49779 & 46922 & -5.74 \\
\hline
\end{tabular}

effort than using traditional computer languages and makes it easy for model expansion. And most of the core elements contained in this model are presented in "Appendices".

\subsection{Model testing}

The developed YulinSD model was verified with the data of 2000-2005, because there are 139 variables in the model and it is difficult to examine, so we chose total population (TP), urbanization population (UP), vegetable field area (VFA), and agricultural water demand (AWD) for examination. With this model, results of total population can be obtained, which are shown in Fig. 6. Table 1 shows the Predictions results for population, vegetable field area and agricultural water demand; most of the variables have low relative errors, which show that the model is reasonable for the actual situation.

\section{Simulation results}

Besides the base run, two additional decision alternatives were examined and compared with the base scenario. They were water supply pattern and the price-control pattern, and both of them were provided by the local authorities based on the previous planning study and other materials. And the simulative alternatives can be attained through adjusting variables and parameters.

With the development of economy, the government pays more attention to water supply, even taking into consideration of the South-to-North Water Diversion in Yulin. According to the previous planning study, there will be four water transfer projects in the future; there are Longkou, Qikou, Daliushu and Tianqiao, all of them have to transfer water from Yellow River. But the situation is that Yellow River has been running out in recent years 
for several times, besides, each of them has a high cost, the marginal cost of additional water is higher and higher. While the perception of water saving is not changed, with more and more supply, they will be more and more useless, and the demand is higher and higher. Moreover, environmental impact is also a serious problem. These economic and environmental reasons eventually make it difficult to achieve sustainable development. Through systematic analysis and simulation, we can get the results of future water demand and water supply pattern as shown in Fig. 7.

With increasing awareness of water-saving in price control program, water market gradually matures, and price as a fundamental economic tool to influence demand, the function is more and more apparent and will finally turn water-supply management to water-demand management to achieve balance between water supply and demand eventually. Figure 8 shows relationships between water demands under different price, and the higher the price is, the smaller is the water demand. With the public awareness growth and water crisis, prices will become an important way to water management, and future water price in Yulin is as shown in Fig. 9.

With the analysis and simulation of the YulinSD, it could be found that the supply-sided approach treats fresh water as a virtually limitless resource, rarely taking fully account of environmental and economic impacts, and continuing to expand infrastructure and develop new water sources has become increasingly expensive. And it is ultimately unsustainable both economically and environmentally (Butler and Memon 2006; Wheida and Verhoeven

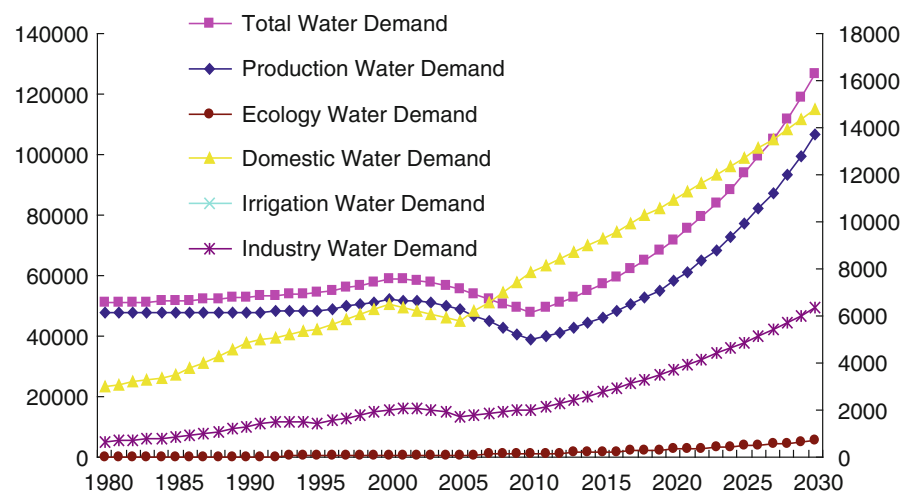

Fig. 7 Water demand of the supply pattern in the future

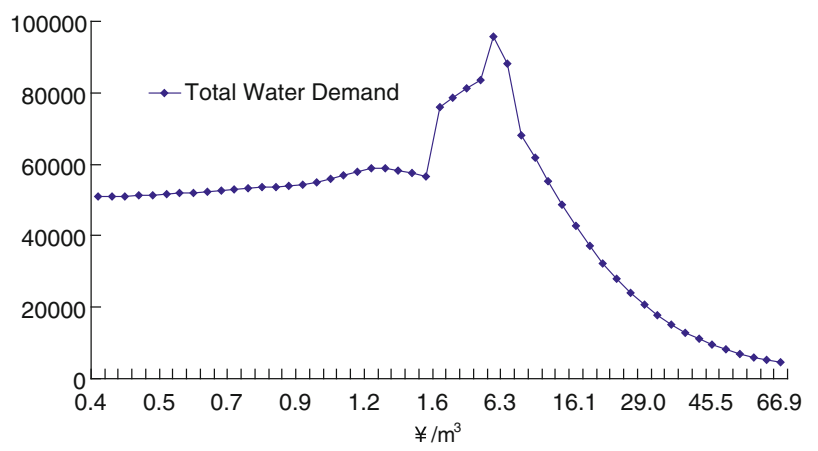

Fig. 8 Relationships between water demand and price of the price control pattern 
Fig. 9 Different kind of water price in the future of the price control pattern

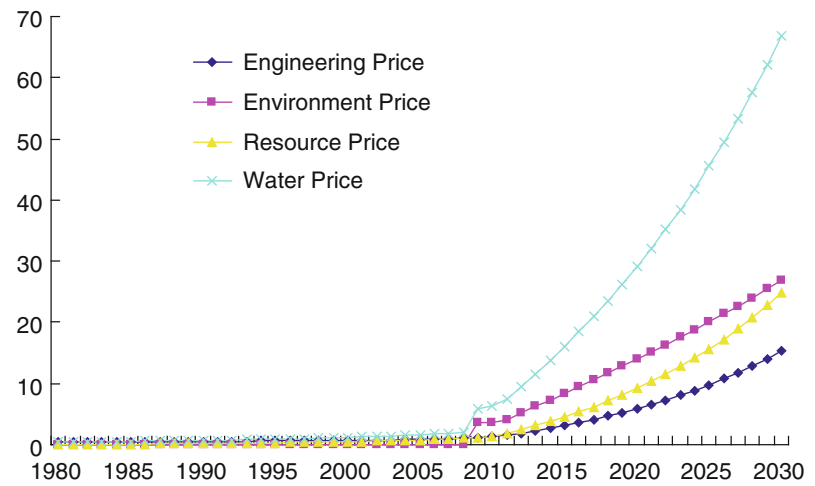

2007). But in the price control pattern, it is useful to solve the water scarcity by efficient and effective utilization of water supply resources, the efficiency and environmental integrity both take into consideration with it, this is known as water-demand management, and considered to be the best potential solution to meet future needs. It has been widely implemented in many areas around world, such as South Africa, Middle East, Canada, et al., and demonstrated that predominant benefits of WDM include both lower costs and environmental protection (Stephenson 1999; Butler and Memon 2006; Gumbo 2004; Wheida and Verhoeven 2007).

With the development of chemical energy industry, economy of Yulin has been developing quickly in recent years. GDP has risen 22 times from 1980 to 2005, and per capita GDP has risen 15 times, but water resources has become a seriously problem than ever before. Data showed that per capita water consumption was $213 \mathrm{~m}^{3} / \mathrm{p}$ in 1980 , but $180 \mathrm{~m}^{3} / \mathrm{p}$ in 2005 , only four-fifth of 1980 . In order to deal with water shortage, many infrastructures have been built in the past years; however, water demand is also increasing, additional with climate change. With more stress on water supply systems, the gap between supply and demand is still apparent, which accelerates the degradation of ecological environment. So it is necessary to carry out WDM in Yulin city to solve the problem.

(1) WDM in Yulin city expects a deep understanding of the basic rules of local water resources system. To achieve the objectives of WDM programme, it should be based on some instruments. All of these instruments applied or not depend on local conditions. So it is necessary to some basic laws of local water system, such as water resources and water environment carrying capacity, the state of water supply systems, water demand characteristics and its impact factors. WDM cases have to be founded on local needs and conditions.

(2) The basis of WDM is government regulations and policies; this means WDM should be implemented with political acceptability.

(3) The aim of WDM is to improve water-use efficiency and finally achieve human-water harmony. As to Yulin city, the main objectives are: in short term (2005-2010), by means of necessary economic measures (water rights, water market, price, et al.) to promote efficient use of water resources in order to achieve the maximization of economic benefits from minimize water resource; in long-term (2010-2020), WDM programme will focus on quality requirements, which becomes the main target. Through optimization between economic and ecology, it will realize a balance between the competing needs and desires of human social and economic systems and the integrity of aquatic ecosystems, and finally achieve the human-water harmony in Yulin city. 
(4) The main tools used to achieve WDM objectives in Yilin city include legislation, institutional arrangements, flow metering, leakages reduction to improve efficiency of water use, wastewater recycle, water allocation between multiple sectors, water price, public education to improve awareness of water saving, etc. And the achieved through collaboration between water planners, water service providers and end-users.

\section{Conclusion}

In this paper, we present an SD modelling framework for understanding and analysing the complex dynamics of supply and demand in Yulin City. The model is used to assess the impacts of various supply and demand management measures. Simulation results show that the current management regime cannot maintain the socio-economic and ecological sustainability in the region. Although additional infrastructure can cover the water deficit in the short period, it cannot cope with the increasing irrigation and domestic requirements. In addition, the costs for operating and maintaining infrastructure are increasing to a level that may not be politically and socially acceptable. Instead, results indicate that a portfolio of demand management instruments and conservation measures is the most sustainable strategy for maintaining the economic and ecological status of the region.

Two considerations are noteworthy. First, the model should be regarded as a policy analysis tool that enables decision makers to learn about the system dynamics, explore and assess alternatives, rather than a predictive tool that generates accurate predictions of the resource future. Second, the reported scenarios still represent an optimistic view of the water future in Yulin as they not consider the plausible impacts of climate change on supply and demand. Adding climate change to the picture will require changes in the dynamic hypothesis, and consequently, the model results. We propose this as an interesting point for future research.

Acknowledgments $\mathrm{We}$ are grateful to the National Basic Research Program of China (No. 2010CB951104), (No. 2010CB951103) and Non-profit Industry Program of the Ministry of Water Resource of the People's Republic of China (No. 200801001) for financial support of this research. Thanks also to the helpful comments received from the anonymous reviewers and the editors.

\section{Appendices}

\section{Appendix 1}

See Table 2.

Table 2 Abbreviations of variables and parameters in the YulinSD model

\begin{tabular}{llll}
\hline Number & Abbreviation & Name & Unit \\
\hline 1 & TP & Total population & $10^{4}$ people \\
2 & CHP & Change of population & $10^{4}$ people/year \\
3 & CRP & Change rate of population & $\%$ \\
4 & UP & Urbanization population & $10^{4}$ people \\
5 & UR & Urbanization rate & $\%$ \\
6 & TUR & Table function of urbanization rate & $\%$ \\
\hline
\end{tabular}


Table 2 continued

\begin{tabular}{|c|c|c|c|}
\hline Number & Abbreviation & Name & Unit \\
\hline 7 & $\mathrm{RP}$ & Rural population & $10^{4}$ people \\
\hline 8 & TQU & Table function of quota for urbanization & 1/p.d \\
\hline 9 & QU & Quota for urbanization & 1/p.d \\
\hline 10 & UDWD & Urbanization domestic water demand & $10^{4} \mathrm{~m}^{3}$ \\
\hline 11 & TQUE & Table function of quota for urbanization ecology & 1/p.d \\
\hline 12 & QUE & Quota for urbanization ecology & 1/p.d \\
\hline 13 & UEWD & Urbanization ecology water demand & $10^{4} \mathrm{~m}^{3}$ \\
\hline 14 & TQR & Table function of quota for rural & 1/p.d \\
\hline 15 & QR & Quota for rural & 1/p.d \\
\hline 16 & RDWD & Rural domestic water demand & $10^{4} \mathrm{~m}^{3}$ \\
\hline 17 & DWD & Domestic water demand & $10^{4} \mathrm{~m}^{3}$ \\
\hline 18 & NR & Natural runoff & $\mathrm{mm}$ \\
\hline 19 & $\mathrm{BF}$ & Base flow & $\mathrm{mm}$ \\
\hline 20 & PUWD & Purification water demand & $\mathrm{mm}$ \\
\hline 21 & IEWD & Inside ecological water demand & $10^{4} \mathrm{~m}^{3}$ \\
\hline 22 & GRDFA & Growth rate of defending forestry area & $\%$ \\
\hline 23 & GDFA & Growth of defending forestry area & $10^{3}$ ha/year \\
\hline 24 & DFADFWD & Defending forestry area & $10^{3}$ ha \\
\hline 25 & TQDFWD & Table function of quota for defending forestry water Demand & $10^{4} \mathrm{~m}^{3} / \mathrm{ha}$ \\
\hline 26 & QDFWD & Quota for defending forestry water demand & $10^{4} \mathrm{~m}^{3} / \mathrm{ha}$ \\
\hline 27 & DFWD & Defending forestry water demand & $10^{4} \mathrm{~m}^{3}$ \\
\hline 28 & OEWD & Outside ecological water demand & $10^{4} \mathrm{~m}^{3}$ \\
\hline 29 & EWD & Ecological water demand & $10^{4} \mathrm{~m}^{3}$ \\
\hline 30 & FOA & Forestry area & $10^{3}$ ha \\
\hline 31 & CFOA & Change of forestry area & $10^{3}$ ha/year \\
\hline 32 & CRFOA & Change rate of forestry area & $\%$ \\
\hline 33 & TQFOWD & Table function of quota for forestry water demand & $10^{4} \mathrm{~m}^{3} / \mathrm{ha}$ \\
\hline 34 & QFOWD & Quota for forestry water demand & $10^{4} \mathrm{~m}^{3} / \mathrm{ha}$ \\
\hline 35 & FOWD & Forestry water demand & $10^{4} \mathrm{~m}^{3}$ \\
\hline 36 & GA & Grass area & $10^{3}$ ha \\
\hline 37 & CGA & Change of grass area & $10^{3}$ ha/year \\
\hline 38 & CRGA & Change rate of grass area & $\%$ \\
\hline 39 & TQGWD & Table function of quota for grass water demand & $10^{4} \mathrm{~m}^{3} / \mathrm{ha}$ \\
\hline 40 & QGWD & Quota for grass water demand & $10^{4} \mathrm{~m}^{3} / \mathrm{ha}$ \\
\hline 41 & GWD & Grass water demand & $10^{4} \mathrm{~m}^{3}$ \\
\hline 42 & IFA & Irrigated farmland area & $10^{3}$ ha \\
\hline 43 & CIFA & Change of irrigated farmland area & $10^{3}$ ha/year \\
\hline 44 & CRIFA & Change rate of irrigated farmland area & $\%$ \\
\hline 45 & TQIFWD & Table function of quota for irrigated farmland water Demand & $10^{4} \mathrm{~m}^{3} / \mathrm{ha}$ \\
\hline 46 & QIFWD & Quota for irrigated farmland water demand & $10^{4} \mathrm{~m}^{3} / \mathrm{ha}$ \\
\hline 47 & IFWD & Irrigated farmland water demand & $10^{4} \mathrm{~m}^{3}$ \\
\hline 48 & VFA & Vegetable field area & $10^{3}$ ha \\
\hline 49 & CVFA & Change of vegetable field area & $10^{3}$ ha/year \\
\hline
\end{tabular}


Table 2 continued

\begin{tabular}{|c|c|c|c|}
\hline Number & Abbreviation & Name & Unit \\
\hline 50 & CRVFA & Change rate of vegetable field area & $\%$ \\
\hline 51 & TQVFWD & Table function of quota for vegetable field water Demand & $10^{4} \mathrm{~m}^{3} / \mathrm{ha}$ \\
\hline 52 & QVFWD & Quota for vegetable field water demand & $10^{4} \mathrm{~m}^{3} / \mathrm{ha}$ \\
\hline 53 & VFWD & Vegetable field water demand & $10^{4} \mathrm{~m}^{3}$ \\
\hline 54 & PFA & Paddy field area & $10^{3}$ ha \\
\hline 55 & CPFA & Change of paddy field area & $10^{3}$ ha/year \\
\hline 56 & CRPFA & Change rate of paddy field area & $\%$ \\
\hline 57 & TQPFWD & Table function of quota for paddy field water demand & $10^{4} \mathrm{~m}^{3} / \mathrm{ha}$ \\
\hline 58 & QPFWD & Quota for paddy field water demand & $10^{4} \mathrm{~m}^{3} / \mathrm{ha}$ \\
\hline 59 & PFWD & Paddy field water demand & $10^{4} \mathrm{~m}^{3}$ \\
\hline 60 & IRWD & Irrigation water demand & $10^{4} \mathrm{~m}^{3}$ \\
\hline 61 & SAA & Small animal amount & $10^{4} \mathrm{p}$ \\
\hline 62 & CRSAA & Change rate of small animal amount & $\%$ \\
\hline 63 & CSAA & Change of small animal amount & $10^{4} \mathrm{p} /$ year \\
\hline 64 & TQSAWD & Table function of quota for small animal water demand & 1/p.d \\
\hline 65 & QSAWD & Quota for small animal water demand & 1/p.d \\
\hline 66 & SAWD & Small animal water demand & $10^{4} \mathrm{~m}^{3}$ \\
\hline 67 & BAA & Big animal amount & $10^{4} \mathrm{p}$ \\
\hline 68 & CRBAA & Change rate of big animal amount & $\%$ \\
\hline 69 & CBAA & Change of big animal amount & $10^{4} \mathrm{p} /$ year \\
\hline 70 & TQBAWD & Table function of quota for big animal water demand & 1/p.d \\
\hline 71 & QBAWD & Quota for big animal water demand & 1/p.d \\
\hline 72 & BAWD & Big animal water demand & $10^{4} \mathrm{~m}^{3}$ \\
\hline 73 & AHWD & Animal husbandry water demand & $10^{4} \mathrm{~m}^{3}$ \\
\hline 74 & FIPA & Fishery pound area & $10^{3}$ ha \\
\hline 75 & CFIPA & Change of fishery pound area & $10^{3} \mathrm{ha} /$ year \\
\hline 76 & CRFIPA & Change rate of fishery pound area & $\%$ \\
\hline 77 & TQFIWD & Table function of quota for fishery water demand & $10^{4} \mathrm{~m}^{3} / \mathrm{ha}$ \\
\hline 78 & QFIWD & Quota for fishery water demand & $10^{4} \mathrm{~m}^{3} / \mathrm{ha}$ \\
\hline 79 & FIWD & Fishery water demand & $10^{4} \mathrm{~m}^{3}$ \\
\hline 80 & FAFWD & Forestry, animal husbandry and fishery water demand & $10^{4} \mathrm{~m}^{3}$ \\
\hline 81 & AWD & Agricultural water demand & $10^{4} \mathrm{~m}^{3}$ \\
\hline 82 & TWD & Total water demand & $10^{4} \mathrm{~m}^{3}$ \\
\hline 83 & WSR & Water shortage rate & $\%$ \\
\hline 84 & GRRWS & Growth rate of reservoir water supply & $\%$ \\
\hline 85 & GRWS & Growth of reservoir water supply & $10^{4} \mathrm{~m}^{3} /$ year \\
\hline 86 & RWS & Reservoir water supply & $10^{4} \mathrm{~m}^{3}$ \\
\hline 87 & GRDWS & Growth rate of division water supply & $\%$ \\
\hline 88 & GDWS & Growth of division water supply & $10^{4} \mathrm{~m}^{3} /$ year \\
\hline 89 & DWS & Division water supply & $10^{4} \mathrm{~m}^{3}$ \\
\hline 90 & GRPWS & Growth rate of pump water supply & $\%$ \\
\hline 91 & GPWS & Growth of pump water supply & $10^{4} \mathrm{~m}^{3} /$ year \\
\hline
\end{tabular}


Table 2 continued

\begin{tabular}{|c|c|c|c|}
\hline Number & Abbreviation & Name & Unit \\
\hline 92 & PWS & Pump water supply & $10^{4} \mathrm{~m}^{3}$ \\
\hline 93 & GROWS & Growth rate of other water supply & $\%$ \\
\hline 94 & GOWS & Growth of other water supply & $10^{4} \mathrm{~m}^{3} /$ year \\
\hline 95 & OWs & Other water supply & $10^{4} \mathrm{~m}^{3}$ \\
\hline 96 & SWS & Surface water supply & $10^{4} \mathrm{~m}^{3}$ \\
\hline 97 & GRGOWS & Growth rate of groundwater water supply & $\%$ \\
\hline 98 & GGWS & Growth of groundwater water supply & $10^{4} \mathrm{~m}^{3} /$ year \\
\hline 99 & GWS & Groundwater water supply & $10^{4} \mathrm{~m}^{3}$ \\
\hline 100 & TWT & Table function of water transfer & $10^{4} \mathrm{~m}^{3}$ \\
\hline 101 & WT & Water transfer & $10^{4} \mathrm{~m}^{3}$ \\
\hline 102 & WWT & Wastewater treatment & $10^{4} \mathrm{~m}^{3}$ \\
\hline 103 & GWWT & Growth of wastewater treatment & $\%$ \\
\hline 104 & GRWWT & Growth rate of wastewater treatment & $10^{4} \mathrm{~m}^{3} /$ year \\
\hline 105 & TWS & Total water supply & $10^{4} \mathrm{~m}^{3}$ \\
\hline 106 & GR1GDP & Growth rate 1 of gross domestic product & $\%$ \\
\hline 107 & GRGDP & Growth rate of gross domestic product & $\%$ \\
\hline 108 & GGDP & Growth of gross domestic product & $10^{4} ¥ /$ year \\
\hline 109 & GDP & Gross domestic product & $10^{4} ¥$ \\
\hline 110 & IO & Industrial output & $10^{4} ¥$ \\
\hline 111 & PIO & Percentage of industrial output & $\%$ \\
\hline 112 & TPIO & Table function of percentage of industrial output & $\%$ \\
\hline 113 & TQIWD & Table function of quota for industrial water demand & $\mathrm{m}^{3} / 10^{4} ¥$ \\
\hline 114 & QIWD & Quota for industrial water demand & $\mathrm{m}^{3} / 10^{4} ¥$ \\
\hline 115 & IWD & Industrial water demand & $10^{4} \mathrm{~m}^{3}$ \\
\hline 116 & IW & Industrial wastewater & $10^{4} \mathrm{~m}^{3}$ \\
\hline 117 & DW & Domestic wastewater & $10^{4} \mathrm{~m}^{3}$ \\
\hline 118 & TW & Total wastewater & $10^{4} \mathrm{~m}^{3}$ \\
\hline 119 & TIO & Tertiary industrial output & $10^{4} ¥$ \\
\hline 120 & PIT & Percentage between industrial and tertiary industrial & $\%$ \\
\hline 121 & TPIT & $\begin{array}{l}\text { Table function of percentage between industrial and Tertiary } \\
\text { Industrial }\end{array}$ & $\%$ \\
\hline 122 & QTIWD & Quota for tertiary industrial water demand & $\mathrm{m}^{3} / 10^{4} ¥$ \\
\hline 123 & TIWD & Tertiary industrial water demand & $10^{4} \mathrm{~m}^{3}$ \\
\hline 124 & PWD & Production water demand & $10^{4} \mathrm{~m}^{3}$ \\
\hline 125 & GRWI & Growth rate of water investment & $\%$ \\
\hline 126 & GWI & Growth of water investment & $10^{4} ¥ /$ year \\
\hline 127 & WI & Water investment & $10^{4} ¥$ \\
\hline 128 & $\mathrm{CD}$ & Cost for design & $10^{4} ¥$ \\
\hline 129 & $\mathrm{CM}$ & Cost for management & $10^{4} ¥$ \\
\hline 130 & $\mathrm{CP}$ & Cost for planning & $10^{4} ¥$ \\
\hline 131 & $\mathrm{CO}$ & Cost for operation & $10^{4} ¥$ \\
\hline
\end{tabular}


Table 2 continued

\begin{tabular}{llll}
\hline Number & Abbreviation & Name & Unit \\
\hline 132 & CWT & Cost for wastewater treatment & $10^{4} ¥$ \\
133 & REP & Resource price & $¥$ \\
134 & ENP & Engineering price & $¥$ \\
135 & ERP & Environment price & $¥$ \\
136 & WP & Water price & $¥$ \\
137 & P & Profit & $10^{4} ¥$ \\
138 & T & Taxes & $10^{4} ¥$ \\
139 & $\mathrm{~S}$ & Subsidies & $10^{4} ¥$ \\
\hline
\end{tabular}

Appendix 2: Main equations of the YulinSD model

(1) $\operatorname{GRGDP}=(0.09+\operatorname{RAMP}(-0.05,10,20) \cdot(1-\mathrm{WSR} \cdot 5))$

(2) GR1GDP $=$ MAX(GRGDP, 0.08)

(3) GGDP $=$ GDP $\cdot$ GR1GDP

(4) GDP $=$ INTEG(GGDP, 72879)

(5) $\quad \mathrm{TIO}=\mathrm{GDP} \cdot \mathrm{PIT}$

(6) TPIT([(1980, 0) - (2050, 1)], (1980, 0.17), (1985, 0.2), (1990, 0.3), (1995, 0.35), (2000, 0.31), (2005, 0.28), (2010, 0.35), (2020, 0.38), (2030, 0.4))

(7) $\mathrm{PIT}=\mathrm{TPIT}(\mathrm{Time})$

(8) TPIO([(1980, 0) - (2050, 1)], (1980, 0.195), (1985, 0.193), (1990, 0.21), (1995, 0.36), (2000, 0.5), (2005, 0.67), (2010, 0.6), (2020, 0.55), (2030, 0.5))

(9) $\mathrm{PIO}=\mathrm{TPIO}(\mathrm{Time})$

(10) $\mathrm{IO}=\mathrm{GDP} \cdot \mathrm{PIO}$

(11) TQIWD([(1980, 0) - (2050, 500)] , (1980, 468), (1985, 411), (1990, 389), (1995, 170), (2000, 118 ), (2005, 52), (2010, 46), (2020, 43), (2030, 37))

(12) $\quad$ QIWD $=$ TQIWD(Time)

(13) QTIWD $=13$

(14) $\mathrm{CRP}=0.0166$

(15) $\mathrm{CHP}=\mathrm{TP} \cdot \mathrm{CRP}$

(16) $\mathrm{TP}=$ INTEG(CHP, 233.1)

(17) TUR([(1980, 0) - (2050, 1)], (1980, 0.07), (1985, 0.092), (1990, 0.096), (1995, 0.115), (2000, 0.15), (2005, 0.165), (2010, 0.201), (2020, 0.288), (2030, 0.375))

(18) UR $=$ TUR(Time)

(19) $\mathrm{UP}=\mathrm{UR} \cdot \mathrm{TP}$

(20) $\mathrm{RP}=\mathrm{TP}-\mathrm{UP}$

(21) TQU([(1980, 60) - (2050, 150)], (1980, 67.6), (1985, 74.8), (1990, 83.3), (1995, 88.7), (2000, 98.6), (2005, 101), (2010, 97), (2020, 105), (2030, 110))

(22) $\mathrm{QU}=\mathrm{TQU}(\mathrm{Time})$

(23) TQUE([(1980, 0) - (2050, 30)] , (1980, 5), (1985, 6), (1990, 7), (1995, 6), (2000, 7), (2005, 8$),(2010,10),(2020,13),(2030,15))$

(24) QUE $=$ TQUE(Time)

(25) TQR([(1980, 30) - (2050, 60)], (1980, 33), (1985, 34), (1990, 45), (1995, 45), (2000, 47), (2005, 34), (2010, 46), (2020, 51), (2030, 56)) 
(26) $\mathrm{QR}=\mathrm{TQR}($ Time)

(27) GRWI $=0.015$

(28) GWI = GDP $\cdot$ GRWI

(29) $\mathrm{WI}=$ INTEG(GWI, 2550)

(30) $\mathrm{CO}=\mathrm{WI} \cdot 0.3$

(31) $\mathrm{CP}=\mathrm{WI} \cdot 0.15$

(32) $\mathrm{CD}=\mathrm{WI} \cdot 0.15$

(33) $\mathrm{CM}=\mathrm{WI} \cdot 0.2$

(34) $\mathrm{CWT}=$ IF THEN ELSE(Time $>2008$, WI $\cdot 0.2,0)$

(35) $\quad \mathrm{ERP}=\mathrm{CWT} / \mathrm{TW}$

(36) $\mathrm{P}=$ TWS $\cdot 0.8$

(37) $\mathrm{S}=\mathrm{P} \cdot 0.45$

(38) $\mathrm{T}=\mathrm{P} \cdot 0.05$

(39) $\mathrm{ENP}=(\mathrm{S}+\mathrm{CO}+\mathrm{T}) / \mathrm{TWS}$

(40) $\mathrm{REP}=(\mathrm{CD}+\mathrm{CM}+\mathrm{CP}) / \mathrm{TWS}$

(41) $\mathrm{WP}=\mathrm{ENP}+\mathrm{ERP}+\mathrm{REP}$

(42) CRPFA $=0.0131$

(43) $\mathrm{CPFA}=\mathrm{PFA} \cdot \mathrm{CRPFA}$

(44) PFA = INTEG(CPFA, 98.39)

(45) TQPFWD([(1980, 0) - (2050, 400)], (1980, 390), (1985, 362), (1990, 322), (1995, 294), (2000, 273), (2005, 255), (2010, 140), (2020, 129), (2030, 122))

(46) QVPWD = TQVPWD(Time)

(47) $\mathrm{PFWD}=\mathrm{QPFWD} \cdot \mathrm{PFA}$

(48) $\mathrm{CRIFA}=-0.04$

(49) $\mathrm{CIFA}=$ IFA $\cdot$ CRIFA

(50) $\quad$ IFA $=$ INTEG(CIFA, 4.14)

(51) TQIFWD([(1980, 0) - (2050, 2000)], (1980, 1066), (1985, 1024), (1990, 972), (1995, 911), (2000, 809), (2005, 1187), (2010, 1057), (2020, 0), (2030, 0))

(52) QIFWD = TQIFWD(Time)

(53) IFWD $=$ QIFWD $\cdot$ IFA

(54) $\mathrm{PUWD}=\mathrm{NR} \cdot 0.05$

(55) $\mathrm{IEWD}=\mathrm{BF}+\mathrm{PUWD}$

(56) $\mathrm{UEWD}=\mathrm{UP} \cdot \mathrm{QUE}$

(57) GRRWS $=0.015$

(58) GRWS = RWS · GRRWS

(59) RWS = INTEG(GRWS, 155)

(60) GRDWS $=-0.0008$

(61) GDWS = DWS · GRDWS

(62) DWS = INTEG(GDWS, 26194)

(63) GRPWS $=0.0035$

(64) GPWS = GRPWS $\cdot$ PWS

(65) PWS = INTEG (GPWS, 7601)

(66) $\mathrm{SWS}=\mathrm{DWS}+\mathrm{PWS}+\mathrm{RWS}$

(67) GROWS $=$ IF THEN ELSE $($ Time $>2005,0.03,0.01)$

(68) GOWS $=$ GROWS $\cdot$ OWS

(69) OWS = INTEG (GOWS, 20) 
(70) TWT([(1980, 0) - (2100, 100000)], (1980, 0), (2019, 0), (2020, 4500), (2030, 92000))

(71) $\mathrm{WT}=$ TWT (Time)

(72) GRGWS $=0.0025$

(73) GGWS = GWS · GRGWS

(74) GWS $=$ INTEG(GGWS, 8882)

(75) TWS $=$ OWS + GWS + SWS + WT

(76) $\quad$ GRDFA $=0.1$

(77) GDFA = DFA $\cdot$ GRDFA

(78) DFA = INTEG(GDFA, 20)

(79) $\mathrm{DFWD}=\mathrm{DFA} \cdot \mathrm{QDFWD} / 10000$

(80) OEWD = UEWD + DFWD

(81) EWD = IEWD + OEWD

(82) GRFIPA $=0.00041$

(83) GFIPA $=$ FIPA $\cdot$ GRFIPA

(84) FIPA = INTEG (GFIPA, 0.55)

(85) TQFIWD([(1980, 0) - (2050, 1500)], (1980, 906), (1985, 1099), (1990, 1192), (1995, 890), (2000, 888), (2005, 1285), (2010, 1278), (2020, 1218), (2030, 1165))

(86) $\quad$ QFIWD = TQFIWD (Time)

(87) FIWD $=$ QFIWD $\cdot$ FIPA

(88) $\quad$ CRVFA $=0.1$

(89) $\quad$ CVFA $=$ VFA $\cdot$ CRVFA

(90) $\quad$ VFA $=$ INTEG(CVFA, 1.94)

(91) TQVFWD([(1980, 0) - (2050, 1000)], (1980, 989), (1985, 900), (1990, 874), (1995, 843), (2000, 808), (2005, 327), (2010, 318), (2020, 308), (2030, 300))

(92) QVFWD = TQVFWD(Time)

(93) $\quad$ VFWD $=$ QVFWD $\cdot$ VFA

(94) IRWD $=$ IFWD + PFWD + WWD

(95) $\quad \mathrm{CRGA}=0.024$

(96) $\mathrm{CGA}=\mathrm{GA} \cdot \mathrm{CRGA}$

(97) $\mathrm{GA}=\mathrm{INTEG}(\mathrm{CGA}, 0.65)$

(98) TQGWD([(1980, 0) - (2050, 400)], (1980, 382), (1985, 370), (1990, 352), (1995, 223), (2000, 217), (2005, 238), (2010, 205), (2020, 195), (2030, 187))

(99) QGWD = TQGWD(Time)

(100) GWD $=$ QGWD $\cdot$ GA

(101) $\mathrm{CRFOA}=0.06$

(102) $\mathrm{CFOA}=\mathrm{FOA} \cdot \mathrm{CRFOA}$

(103) $\mathrm{FOA}=\mathrm{INTEG}(\mathrm{CFOA}, 1.32)$

(104) TQFOWD([(1980, 0) - (2050, 400)] , (1980, 384), (1985, 379), (1990, 389), (1995, 240), (2000, 199), (2005, 193), (2010, 178), (2020, 168), (2030, 159))

(105) QFOWD = TQFOWD(Time)

(106) FOWD $=$ QFOWD $\cdot$ FOA

(107) $\mathrm{CRSAA}=0.00064$

(108) $\quad$ CSAA $=$ SAA.CRSAA

(109) $\quad$ SAA = INTEG(CSAA, 272.69) 
(110) TQSAWD([(1980, 5) - (2050, 40)], (1980, 9), (1985, 10), (1990, 11), (1995, 11), (2000, 11), (2005, 12), (2010, 12), (2020, 14), (2030, 16))

(111) QSAWD = TQSAWD(Time)

(112) SAWD = SAA·QSAWD $\cdot 365 / 1000$

(113) $\quad \mathrm{CRBAA}=0.00039$

(114) $\mathrm{CBAA}=\mathrm{BAA} \cdot \mathrm{CRBAA}$

(115) $\quad \mathrm{BAA}=$ INTEG(CBAA, 34.23)

(116) TQBAWD $([(1980,10)-(2050,50)],(1980,19),(1985,24),(1990,26),(1995$, 26), (2000, 28), (2005, 19), (2010, 30), (2020, 33), (2030, 36))

(117) QBAWD = TQBAWD(Time)

(118) $\quad \mathrm{BAWD}=\mathrm{BAA} \cdot \mathrm{QBAWD} \cdot 365 / 1000$

(119) AHWD = BAWD + SAWD

(120) FAFWD $=$ FOWD + FIWD + AHWD + GWD

(121) $\mathrm{AWD}=\mathrm{IRWD}+\mathrm{FAFWD}$

(122) $\quad$ IWD $=$ IO $\cdot$ QIWD $/ 10000$

(123) $\quad$ IW $=$ IWD $\cdot 0.3$

(124) $\quad$ PWD $=$ AWD + IWD + TIWD

(125) $\quad \mathrm{UDWD}=\mathrm{UP} \cdot \mathrm{QU} \cdot 365 / 1000$

(126) $\mathrm{RDWD}=\mathrm{RP} \cdot \mathrm{QR} \cdot 365 / 1000$

(127) $\mathrm{DWD}=\mathrm{RDWD}+\mathrm{UDWD}$

(128) $\mathrm{TW}=\mathrm{IW}+\mathrm{DW}$

(129) $\quad \mathrm{DW}=\mathrm{DWD} \cdot 0.8$

(130) $\mathrm{TWD}=(3 / \mathrm{WP})^{\wedge}(((63317-(\mathrm{PWD}+\mathrm{EWD}+\mathrm{TDWD})) /(1-\mathrm{WP})) \cdot(\mathrm{WP} /$ $(\mathrm{PWD}+\mathrm{EWD}+\mathrm{TDWD}))) \cdot 63317$

(131) $\mathrm{WSR}=\mathrm{IF}$ THEN ELSE $($ TWS - TWD $<0,($ TWD - TWS $) / T W D, 0)$

\section{References}

Ahmad, S., \& Simonovic, S. P. (2004). Spatial system dynamics: New approach for simulation of water resources systems [J]. Journal of Computing in Civil Engineering, 18(4), 331-340.

Born, S., \& Sonzogni, W. (1995). Integrated environmental management: Strengthening the conceptualization. Environmental Management [J], 19(2), 167-181.

Brierley, G., \& Fryirs, K. A. (Eds.). (2008). River futures: An integrative scientific approach to river repair. Washington, DC: Island Press.

Brown, L., \& Flavin, C. (1999). A new economy for a new century. State of the World. 3-21.

Butler, D., \& Memon, F. A. (2006). Water demand management [M]. London: IWA Publishing.

Elmahdi, A., Malano, H., \& Etchells, T. (2007). Using system dynamics to model water-reallocation [J]. Environmentalist, 27, 3-12.

Glantz, M. (1999). Sustainable development and creeping environmental problems. In M. Glantz (Ed.), Creeping environmental problems and sustainable development in the Aral Sea basin (pp. 1-25). Cambridge: Cambridge University Press.

Gumbo, B. (2004). The status of water demand management in selected cities of southern Africa [J]. Physics and Chemistry of the Earth, 29, 1225-1331.

Guo, H. C., Liu, L., \& Huang, G. H. (2001). A system dynamics approach for regional environmental planning and management: A study for the Lake Erhai Basin [J]. Journal of Environmental Management, 61, 93-111.

Hjorth, P., \& Bagheri, A. (2006). Navigating towards sustainable development: A system dynamics approach [J]. Futures, 38(1), 74-92.

Holling, C., \& Meffe, G. (1996). Command and control and the pathology of natural resource management [J]. Conservation Biology, 10(2), 328-337. 
Jakeman, A., Letcher, R., Newham, L., \& Norton, J. (2005). Integrated catchment modelling: Issues and opportunities to support improved sustainability outcomes. In Proceedings of the 29th hydrology and water resources symposium, Canberra, Australia.

Karavezyris, V., Timpe, K. P., \& Marzi, R. (2002). Application of system dynamics and fuzzy logic to forecasting of municipal solid waste [J]. Mathematics and Computers in Simulation, 60, 149-158.

Rogers, P., de Silva, R., \& Bhatia, R. (2002). Water is an economic good: How to use prices to promote equity, efficiency, and sustainability [J]. Water Policy, 4, 1-17.

Savenije, H., \& van der Zaag, P. (2002). Water as an economic good and demand management paradigms with pitfalls [J]. Water International, 27(1), 98-104.

Stephenson, D. (1999). Demand management theory [J]. Water SA, 25(2), 115-122.

Sterman, J. (1994). Learning in and about complex systems [J]. System Dynamics Review, 10, 291.

Sterman, J. (2000). Business dynamics: Systems thinking and modelling for a complex world. Boston: Irwin/ McGraw-Hill.

Sun, Y. F., Guo, H.-C., \& Qu, G.-Y. (2002). A system dynamics approach for sustainable development in the Miyun reservoir area, China [J]. Chinese Geographical Science, 12(2), 157-165.

Ventana Systems, Inc. (2003). Vensim 5 reference manual [M]. (http://www.vensim.com).

Wheida, E., \& Verhoeven, R. (2007). An alternative solution of the water shortage problem in Libya [J]. Water Resource Manage, 21, 961-982.

Winz, I., Brierley, G., \& Trowsdale, S. (2009). The use of system dynamics simulation in water resources management [J]. Water Resources Management, 23(7), 1301-1323.

Wolstenholme, E. (1990). System enquiry: A system dynamics approach. New York, NY, USA: Wiley.

Xu, Z. X., Takeuchi, K., \& Ishidaira, H. (2002). Sustainability analysis for Yellow River water resources using the system dynamics approach [J]. Water Resources Management, 16, 239-261.

Yu, C.-H., Chen, C.-H., \& Lin, C.-F. (2003). Development of system dynamics model for sustainable land use management [J]. Journal of the Chinese Institute of Engineers, 26(5), 607-618.

Zhang, H. L. (2005). Strategic study for water management in China [M]. Nanjing: Southeast University Press.

Zhang, X. H., Zhang, H. W., \& Chen, B. (2008). Water resources planning based on complex system dynamics: A case study of Tianjin city [J]. Communications in Nonlinear Science and Numerical Simulation, 13, 2328-2336. 